\title{
Características de carcaça de vacas de descarte e novilhos mestiços Charolês $\times$ Nelore em confinamento sob diferentes frequências de alimentação
}

\section{Julcemir João Ferreira ${ }^{1}$, Luís Fernando Glasenapp de Menezes ${ }^{2}$, João Restle ${ }^{3}$, Ivan Luiz Brondani $^{4}$, Dari Celestino Alves Filho ${ }^{5}$, Álisson Marian Callegaro ${ }^{6}$}

\author{
1 Bunge Fertilizantes. \\ 2 Universidade Tecnológica Federal do Paraná - Campus Dois Vizinhos. \\ 3 Programa de Pós-graduação em Zootecnia - UFSM. Pesquisador CNPq. \\ ${ }^{4}$ Departamento de Zootecnia da UFSM - Pesquisador do CNPq. \\ ${ }^{5}$ Departamento de Zootecnia - UFSM. \\ ${ }^{6}$ Curso de graduação de Zootecnia - UFSM.
}

RESUMO - O estudo foi realizado com o objetivo de avaliar as características de carcaça de novilhos e vacas de descarte de dois grupos genéticos sob diferentes frequencias de alimentação. Foram utilizados 12 novilhos e 12 vacas de descarte, de modo que cada categoria foi formada de seis animais 5/8 Charolês (C) - Nelore (N) e seis animais 5/8NC, submetidos a três frequencias alimentação; duas vezes ao dia (às 7 e 19 h); três vezes ao dia (às 7, 13 e 19 h); e quatro vezes ao dia (às 7, 11, 15 e 19 h). Os animais foram terminados em confinamento recebendo como volumoso silagem de milho e concentrado à base de farelo de trigo, grão de milho moído, farelo de soja, calcário calcítico e sal, com relação volumoso:concentrado 40:60. O aumento na frequência de alimentação não influenciou a qualidade da carcaça dos animais. As vacas apresentaram maiores pesos de abate e de carcaça quente e fria $(509,7 ; 280,0$; e 277,1 kg) em comparação aos novilhos $(414,5 ; 230,5$ e 228,1 kg), no entanto, os rendimentos de carcaça quente e fria e as perdas por resfriamento foram semelhantes entre novilhos e vacas de descarte. As características que expressam a musculosidade da carcaça foram melhores nas vacas, que apresentaram maior espessura de coxão $(25,88$ vs $23,33 \mathrm{~cm})$. As características métricas foram mais expressivas nas vacas, que tiveram carcaças mais longas $(132,8$ vs $122,3 \mathrm{~cm})$ e maior espessura de gordura $(6,21 \mathrm{vs} 3,83 \mathrm{~mm})$. As vacas também foram superiores quanto aos pesos de dianteiro e traseiro (103,5 e 133,0 kg) em comparação aos novilhos $(84,7$ e $111,8 \mathrm{~kg})$, que apresentaram maior percentual de traseiro na carcaça $(49,06$ vs 48,04\%). Entre os grupos genéticos, os animais 5/8C 3/8N apresentaram maior espessura de coxão, área do músculo Longissimus dorsi e comprimento de carcaça $\left(25,7 \mathrm{~cm} ; 64,0 \mathrm{~cm}^{2}\right.$ e $\left.137,0 \mathrm{~cm}\right)$ em comparação aos $5 / 8 \mathrm{~N} 3 / 8 \mathrm{C}\left(23,5 \mathrm{~cm} ; 57,0 \mathrm{~cm}^{2}\right.$ e $\left.124,8 \mathrm{~cm}\right)$.

Palavras-chave: categoria animal, Charolês, cruzamento, Nelore, rendimento de carcaça

\section{Carcass characteristics of cows and steers from different genetic groups, in feedlot under different feeding frequencies}

\begin{abstract}
The objective of this study was to evaluate carcass characteristics of steers and cull cows from two genetic groups, under different feeding frequencies. Twelve steers and twelve cull cows were used and each category consisted of six animals 5/8 Charolais $(\mathrm{C})$ - Nellore $(\mathrm{N})$ and six animals $5 / 8 \mathrm{NC}$, under three feeding frequencies: twice a day ( 7 a.m. and 7 p.m.); three times a day ( 7 a.m., 1 p.m. and 7 p.m.) and four times a day (7 a.m., 11 a.m., 3 p.m. and 7 p.m.). The animals were feedlot finished receiving corn silage as forage and concentrate based on wheat bran, corn ground, soybean meal, limestone and salt, with a forage:concentrate ratio of 40:60. The increase in feeding frequency did not influence the animal carcass quality. The cows showed higher slaughter, hot and cold carcass weights $(509.7 ; 280.0$; and $277.1 \mathrm{~kg})$ compared to the steers $(414.5 ; 230.5$ and $228.1 \mathrm{~kg})$, but the hot and cold carcass dressing percentages and carcass chilling loss were similar in the steers and cull cows. The characteristics that express carcass muscularity were better in the cows that had greater thigh thickness $(25.88$ vs $23.33 \mathrm{~cm})$. The metrical characteristics were more expressive in the cows which had longer carcasses $(132.8 \mathrm{vc} 122.3 \mathrm{~cm})$ and greater fat thickness $(6.21 \mathrm{vs} 3.83 \mathrm{~mm})$. The cows also were superior for forequarter and sawcut weights (103.5 and $133 \mathrm{~kg}$ ) compared to the steers $(84.7$ and $111.8 \mathrm{~kg}$ ), which presented higher sawcut percentage in the carcass (49.06 vs $48.04 \%$ ). Between the genetic groups, $5 / 8 \mathrm{C} 3 / 8 \mathrm{~N}$ animals presented higher thigh thickness, Longissimus dorsi area and carcass length $\left(25.7 \mathrm{~cm} ; 64 \mathrm{~cm}^{2}\right.$ and $\left.137 \mathrm{~cm}\right)$ compared to $5 / 8 \mathrm{~N} 3 / 8 \mathrm{C}\left(23.5 \mathrm{~cm} ; 57 \mathrm{~cm}^{2}\right.$ and $\left.124.8 \mathrm{~cm}\right)$.
\end{abstract}

Key Words: animal category, carcass dressing percentage, Charolais, crossbred, Nellore 


\section{Introdução}

A crescente adoção de inovações tecnológicas nos sistemas criatórios de bovinos de corte no Brasil tende a resultar, embora lentamente, em uma modificação da estrutura de composição dos rebanhos. A característica empresarial que tem assumido o segmento pecuário exige constante atenção dos produtores em atingir índices de produção que aperfeiçoem o uso dos alimentos e os custos de produção, refletindo em margens que permitam a manutenção da atividade. Nesse contexto, observam-se importantes técnicas de manejo, como a utilização de várias alternativas na alimentação para terminação em sistemas mais intensivos, como o confinamento ou semiconfinamento. Com a técnica do confinamento é cada vez mais difundida entre produtores, diferentes manejos têm sido testados para aumento da produtividade. Entre eles, o aumento da frequência de alimentação, que estimula o animal a ingerir alimento (Chase et al., 1976), alterando seu padrão de comportamento ingestivo (Fischer et al., 2002), o que pode refletir em aumento no consumo de matéria seca e no desempenho produtivo, podendo influenciar nas características da carcaça.

O conjunto associado dessas tecnologias é a base para maior produção de bezerros e redução na idade de abate dos animais. Nos sistemas mais intensivos e lucrativos da pecuária bovina de corte, são os que abatem os machos com até 2 anos de idade (Vaz et al., 2002a). A nova caracterização da estrutura dos rebanhos mostra tendência de redução na idade de abate dos novilhos e de acasalamento das fêmeas, o que, além de representar maior qualidade do produto final nas prateleiras (Vaz \& Restle, 1998), permite maior pressão de seleção nas matrizes de reposição (Vaz et al., 2002b).

Como efeito secundário, observa-se maior oferta de fêmeas de descarte para os frigoríficos, historicamente próxima dos $45 \%$ do total de animais abatidos (Kuss et al., 2005). O descarte das vacas geralmente ocorre no início do período de menor produção forrageira, entre abril e maio, período que esses animais perderão peso na época de restrição até setembro ou outubro, concorrendo por alimento com o rebanho de cria. Portanto, quando é possível terminar esses animais na mesma época do diagnóstico de gestação (inverno/seca), além da menor taxa de lotação para a estação subsequente, é possível obter melhor remuneração por unidade de produto na entressafra (Anualpec, 2006). De acordo com Perobelli et al. (1995), vacas terminadas em campo nativo apresentam menor rendimento de carcaça se comparadas a vacas terminadas em sistemas com suplementação energética.
A composição genética do rebanho pode influenciar na qualidade da carcaça de acordo com as condições alimentares a que os animais são submetidos (Menezes et al., 2005). Koger (1980) cita o cruzamento como forma de acelerar os avanços genéticos, ao inserir genes desejáveis mais rapidamente que os métodos de seleção dentro da mesma raça. O cruzamento entre as raças Charolesa e Nelore vêm sendo amplamente estudado na região central do Rio Grande do Sul e tem por base a expressão da raça européia em ganho de peso e composição em músculo, em combinação à rusticidade e capacidade relativa de antecipação na deposição de gordura, inerente ao Nelore (Menezes et al., 2005).

Este trabalho foi realizado com o objetivo de avaliar as características quantitativas da carcaça de novilhos e vacas oriundos do cruzamento entre as raças Charolesa e Nelore em confinamento sob diferentes frequencias de alimentação.

\section{Material e Métodos}

O experimento foi realizado no Laboratório de Bovinocultura de Corte do Departamento de Zootecnia da Universidade Federal de Santa Maria, situada no município de Santa Maria, região central do Rio Grande do Sul.

Foram avaliadas as características de carcaça de 12 novilhos e 12 vacas de descarte, cada categoria composta de seis $5 / 8$ Charolês $\times$ Nelore $(5 / 8 \mathrm{CN})$ e seis $5 / 8$ Nelore $\times$ Charolês $(5 / 8 \mathrm{NC})$, submetidos a três frequências de alimentação: duas vezes ao dia (às 7 e 19 h); três vezes ao dia (às 7, 13 e 19 h); ou quatro vezes ao dia (às 7, 11, 15 e 19 h). A quantidade de alimento fornecida diariamente foi parcelada em partes iguais, de acordo com a frequencia de alimentação. Todos os animais foram oriundos de mesmo rebanho, com manejo sanitário e nutricional conjunto para cada categoria.

O período de terminação dos animais ocorreu em confinamento por 99 dias, de modo que, ao início desse período, os novilhos apresentavam em média 21 meses de idade e $272 \mathrm{~kg}$ de peso vivo, enquanto as vacas apresentavam em média 66 meses de idade e $340 \mathrm{~kg}$ peso vivo. Os animais foram alojados em instalações com piso pavimentado, boxes de $20 \mathrm{~m}^{2}$, parcialmente cobertos e com $1 \mathrm{~m}$ linear de cocho por animal, de modo que cada boxe continha um animal de cada grupo genético e mesma categoria.

A dieta foi à base de silagem de milho - AG 2020 nos primeiros 48 dias e AG 5011 no período restante (51 dias) e concentrado composto de farelo de trigo, grão de milho moído, farelo de soja, calcário calcítico e sal, com relação volumoso:concentrado de 40:60. A dieta com a silagem AG 
2020 continha $14,4 \%$ proteína bruta (PB) e $2.784 \mathrm{kcal}$ de energia digestível(ED) e aquela com a silagem de milho AG $5011,14,00 \%$ proteína bruta e $2.953 \mathrm{kcal}$ de energia digestível.

$\mathrm{O}$ abate dos animais ocorreu em frigorífico comercial a $25 \mathrm{~km}$ do confinamento, após jejum de sólidos por 12 horas e pesagem para obtenção do peso pré-abate. Após esfola e evisceração, as meias-carcaças foram lavadas, identificadas, pesadas e submetidas a resfriamento por 24 horas a $0^{\circ} \mathrm{C}$. Após o resfriamento, foram obtidos os pesos de carcaça fria e a conformação das carcaças de acordo com metodologia de Müller (1987). Os rendimentos de carcaça quente e fria foram obtidos pelo peso destas em relação ao peso pré-abate, enquanto a quebra ao resfriamento foi obtida pela relação entre peso da carcaça quente e a mesma carcaça após resfriamento.

$\mathrm{Na}$ meia-carcaça direita, foram tomadas as seguintes medidas: comprimento de carcaça, correspondente à medida do bordo anterior do osso púbis ao bordo anterior medial da primeira costela; espessura de coxão, medida com auxílio de compasso posicionado entre a face lateral e a medial da porção superior do coxão; perímetro de braço, correspondendo a circunferência medial do membro; comprimento de perna correspondendo a distância entre o bordo cranial do osso púbis e a articulação tibio-tarsiana. Ainda na meia-carcaça direita, foi obtida peça entre $10^{\mathrm{a}}$ e $12^{\mathrm{a}}$ costelas, a fim de expor o músculo Longissimus dorsi para traçar o seu contorno em papel-vegetal, na altura da $12 \underline{a}$ costela. A área da figura foi posteriormente determinada em mesa digitalizadora utilizando-se o software Site 1.0. No mesmo local, foi medida a espessura de gordura, correspondente à média aritmética de três pontos de mensuração. A meia-carcaça esquerda foi separada nos cortes dianteiro, que incluía pescoço, paleta, braço e cinco costelas anteriores; costilhar, a partir da sexta costela mais os músculos abdominais; e o serrote, constituído pelo posterior da carcaça. Esses cortes foram pesados para posterior cálculo da participação percentual em relação à carcaça fria.

$\mathrm{O}$ delineamento experimental foi o inteiramente casualizado em um arranjo fatorial $3 \times 2 \times 2$ ( 3 frequencias de alimentação $\times 2$ categorias $\times 2$ grupos genéticos). As médias dos parâmetros em estudo foram submetidas à análise de variância. Quando observada diferença a pelo menos $5 \%$ de probabilidade, as médias foram classificadas pelo "teste t" $(\mathrm{P}<0,05)$, pelo procedimento pdiff(SAS, 1997). $\mathrm{O}$ modelo estatístico adotado foi:

$$
\mathrm{Y}_{\mathrm{ijkl}}=\mu+\mathrm{T}_{\mathrm{k}}+\mathrm{C}_{\mathrm{i}}+\mathrm{GG}_{\mathrm{j}}+\left(\mathrm{C}^{*} \mathrm{GG}\right)_{\mathrm{ij}}+\mathrm{E}_{\mathrm{ijkl}}
$$

em que: $\mathrm{Y}_{\mathrm{ijkl}}=$ variáveis dependentes; $\mu$ média de todas as observações; $\mathrm{T}_{\mathrm{k}}=$ efeito da frequencia de alimentação de ordem k (2; 3 ou 4 vezes/dia); $C_{i}=$ efeito da categoria de ordem i (novilho ou vaca); $\mathrm{GG}_{\mathrm{j}}=$ efeito do grupo genético de ordem $\mathrm{j}(5 / 8 \mathrm{CN}$ ou $5 / 8 \mathrm{NC}) ;\left(\mathrm{C}^{*} \mathrm{GG}\right)_{\mathrm{ij}}=$ efeito da interação da categoria i com o grupo genético j; $\mathrm{E}_{\mathrm{ijkl}}=$ efeito residual aleatório.

As interações $T^{*} \mathrm{C}, \mathrm{T}^{*} \mathrm{GG}$ e $\mathrm{T}^{*} \mathrm{C}^{*} \mathrm{GG}$ foram testadas, mas, como não apresentaram efeitos significativos $(\mathrm{P}>0,05)$, foram retiradas do modelo.

\section{Resultados e Discussão}

Não houve interação $(P>0,05)$ entre a frequencia de alimentação da dieta e os demais efeitos estudados. O aumento na frequencia de alimentação não influenciou $(\mathrm{P}>0,05)$ nas características da carcaça. As semelhanças nas características quantitativas da carcaça podem ser atribuídas ao peso de abate semelhante dos animais, já que estas características são altamente relacionadas ao peso de abate dos animais (Arboitte et al. 2004) quando o rendimento de carcaça não é afetado (Faturi et al., 2002). Restle et al. (2002) verificaram coeficiente de correlação altamente positivo do peso de abate com os pesos de carcaça fria, traseiro, dianteiro e costilhar, conformação e área do músculo Longissimus dorsi quando avaliaram as características quantitativas da carcaça de vacas de descarte de diferentes grupos genéticos.

Além do peso de abate, a dieta pode influenciar o rendimento de carcaça, e alterar algumas características quantitativas. Essas diferenças são encontradas quando se fornecem aos animais dietas com diferentes taxas de passagem e poder de enchimento, pois, quando se trabalha com animais de mesmo padrão racial, com pesos de sangue, cabeça, patas, couro, órgãos internos e vísceras semelhantes, o rendimento varia de acordo com o conteúdo gastrintestinal (Faturi et al., 2002). Neste trabalho, as dietas foram semelhantes em todos os tratamentos-modificou-se apenas o manejo alimentar - e foi utilizado o mesmo procedimento de abate, já que o tempo de jejum a que os animais são submetidos antes do abate também pode afetar o rendimento de carcaça. A espessura de gordura de cobertura das carcaças (Tabela 1) foi semelhante entre frequências de alimentação testadas. A deposição de gordura no animal está altamente relacionada ao peso de abate (Kuss et al., 2005), ao grupo genético (Menezes et al., 2005), à idade do animal e à densidade energética da dieta (Restle et al., 2001), todos semelhantes entre todas as frequências de alimentação.

O peso e a porcentagem dos cortes comerciais também não foram afetados $(\mathrm{P}>0,05)$ pelo aumento na frequencia de alimentação. Jardim et al. (1988) verificaram que $58 \%$ da variação total no peso do dianteiro, $50 \%$ da variação total no peso do costilhar e $92 \%$ da variação total no peso do 
Tabela 1 - Características da carcaça de novilhos e vacas de descarte terminados em confinamento com diversas frequencias de alimentação

\begin{tabular}{|c|c|c|c|c|c|}
\hline \multirow[t]{2}{*}{ Item } & \multicolumn{3}{|c|}{ Frequencia de alimentação } & \multirow[t]{2}{*}{ Erro-padrão } & \multirow[t]{2}{*}{ Média } \\
\hline & 2 vezes/dia & 3 vezes/dia & 4 vezes/dia & & \\
\hline Peso de abate, $\mathrm{kg}$ & 458,37 & 463,50 & 464,37 & 19,94 & 462,08 \\
\hline Peso de carcaça fria, $\mathrm{kg}$ & 247,90 & 248,82 & 252,19 & 11,52 & 249,64 \\
\hline Rendimento de carcaça quente, $\%$ & 54,67 & 55,64 & 58,31 & 0,37 & 56,21 \\
\hline Rendimento de carcaça fria, \% & 54,18 & 53,67 & 54,32 & 0,41 & 54,06 \\
\hline Conformação, pontos 1 & 8,37 & 8,62 & 9,25 & 0,43 & 8,75 \\
\hline Maturidade fisiológica, pontos ${ }^{2}$ & 10,50 & 9,37 & 10,50 & 1,08 & 10,12 \\
\hline Comprimento de perna, $\mathrm{cm}$ & 71,37 & 72,06 & 71,37 & 0,85 & 71,60 \\
\hline Comprimento de braço, $\mathrm{cm}$ & 38,87 & 38,50 & 39,37 & 0,67 & 38,91 \\
\hline Comprimento de carcaça, cm & 127,81 & 128,00 & 127,00 & 1,97 & 127,60 \\
\hline Espessura de gordura subcutânea, $\mathrm{mm}$ & 5,81 & 5,50 & 3,75 & 0,62 & 5,02 \\
\hline Dianteiro, $\mathrm{kg}$ & 93,15 & 93,65 & 95,45 & 4,73 & 94,08 \\
\hline Traseiro, \% & 50,61 & 50,00 & 50,77 & 0,29 & 50,46 \\
\hline
\end{tabular}

$\mathrm{P}>0,05$

Tabela 2 - Pesos de carcaça quente e fria, rendimentos de carcaça quente e fria, quebra no resfriamento da carcaça e espessura de gordura subcutânea de novilhos e vacas de descarte terminados em confinamento com diversas frequencias de alimentação

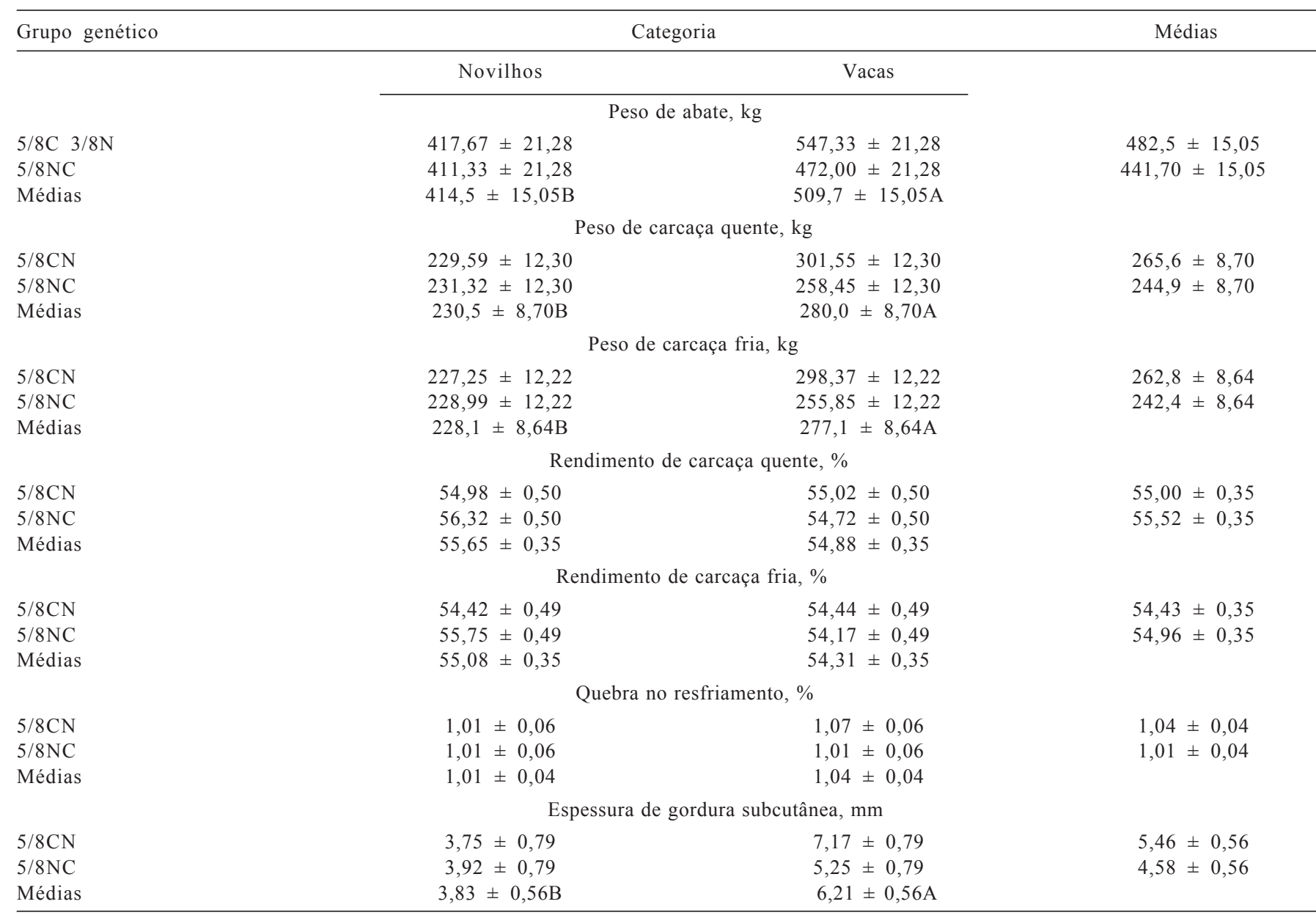

$\mathrm{C}=$ Charolês; $\mathrm{N}=$ Nelore.

A,B Letras maiúsculas diferentes na linha, diferem $(\mathrm{P}<0,05)$ pelo teste $\mathrm{t}$. 
traseiro se devem à variação no peso da carcaça, mas não verificaram influência significativa do peso de carcaça sobre as porcentagens dos cortes comerciais.

Não houve interação $(\mathrm{P}>0,05)$ entre categoria e grupo genético para os pesos de abate e de carcaça quente e fria, os rendimentos de carcaça quente e fria e a quebra durante o resfriamento (Tabela 2).

Não foi observada diferença $(\mathrm{P}>0,05)$ entre os grupos genéticos para o peso de abate, o que confirma os resultados encontrados por Pacheco et al. (2005) e Menezes et al. (2005). No entanto, as vacas foram $23 \%$ superiores $(P<0,05)$ aos novilhos. Essa diferença pode ser considerada normal, uma vez que a comparação foi entre animais adultos (vacas) e jovens (novilhos), inclusive vários autores têm observado resultados semelhantes (Restle et al., 2000; Vaz et al., 2002c). Restle et al. (2001), ao verificarem que novilhas Charolês abatidas aos 3 anos de idade apresentaram menor peso de abate em comparação a vacas de descarte da mesma raça. Esses autores concluíram que as novilhas não haviam completado seu crescimento, tendo em vista seu menor comprimento de carcaça.

As médias dos pesos de carcaça quente e de carcaça fria tiveram mesmo comportamento que o peso de abate, uma vez que os rendimentos de carcaça não variaram $(\mathrm{P}>0,05)$. Ao se ajustar às características para o mesmo peso de abate (co-variável), as diferenças para os pesos de carcaça quente e fria deixaram de ser significativas, o que era esperado, uma vez que essas características têm relação estreita com o peso vivo. Há correlação alta e positiva entre pesos de abate e de carcaça quente $(\mathrm{r}=0,99)$ ou fria $(\mathrm{r}=0,99)$ (Tabela 6$)$.

O rendimento de carcaça foi semelhante para todos os efeitos testados. Vaz et al. (2002c) observaram maior rendimento de carcaça para os novilhos Hereford em comparação a vacas de mesmo genótipo. Ao estudarem animais mestiços Hereford $\times$ Nelore terminados e abatidos com 1 ano de idade, Vaz et al. (2001) quantificaram os órgãos internos e externos de machos castrados e fêmeas e verificaram que o maior rendimento de carcaça dos machos está ligado também ao menor peso do rúmen vazio e do couro e sugeriram que o maior peso do rúmen seria uma necessidade das fêmeas para atender os requerimentos nutricionais bastante elevados durante a gestação e a amamentação. Esses autores atribuíram o maior peso do couro ao maior arqueamento de costelas das fêmeas, aumentando a superfície do animal.

A espessura de gordura subcutânea (EGS) também atua no rendimento, protegendo a carcaça de perdas de líquidos durante o resfriamento (Müller, 1987). As vacas foram superiores $(\mathrm{P}<0,05)$ aos novilhos $\mathrm{e}$, apesar da superioridade em EGS, não diferiram $(\mathrm{P}>0,05)$ quanto à quebra durante o resfriamento. Isso indica que a espessura de gordura obtida nos novilhos foi suficiente para proteger a carcaça de efeitos severos do resfriamento. Esses rendimentos de carcaça são bastante expressivos, o que demonstra a eficiência do confinamento sobre esse fator de desempenho. Segundo Di Marco (1998), espera-se menor rendimento de carcaça em animais alimentados com volumosos mais fibrosos, além do nível de concentrado também exercer influência positiva sobre o rendimento de carcaça.

Vários autores (Galvão et al., 1991; Restle et al., 1999; Menezes et al., 2005) comentaram que animais com maior participação de sangue Nelore têm maiores rendimentos de carcaça. Segundo Menezes et al. (2007), essa relação deve-se aos menores pesos relativos do trato gastrintestinal e das patas e dos pesos absolutos do conjunto dos órgãos internos e do conteúdo do trato gastrintestinal de novilhos com grande participação de sangue Nelore. No entanto, quando estudaram os mesmos grupos genéticos deste estudo, Kuss et al. (2005), trabalhando com vacas de descarte, Menezes et al. (2005) com novilhos jovens e Pacheco et al. (2005), com novilhos jovens e superjovens, não observaram efeito do genótipo sobre o rendimento de carcaça. Catellam et al. (2009) também não observaram efeito do genótipo sobre as características não-integrantes da carcaça. Entretanto, os novilhos apresentaram maior peso relativo do total dos componentes externos e do total dos órgãos vitais, porém essas diferenças não foram suficientes para afetar o rendimento de carcaça desses animais; provavelmente foram compensadas pela maior participação da gordura interna na carcaça das vacas de descarte.

Não houve interação $(P>0,05)$ entre categoria e grupo genético para as características de musculosidade e maturidade fisiológica da carcaça (Tabela 3). Para a conformação, em pontos, que caracteriza a musculosidade de toda a carcaça, não foi observado efeito significativo $(\mathrm{P}>0,05)$ para nenhum dos fatores de estudo, assim, as carcaças foram classificadas como "regulares". Quando o modelo foi ajustado para o mesmo peso de abate, os novilhos apresentaram maior ( $\mathrm{P}=0,009)$ conformação em relação às vacas $(9,64$ vs 7,86 pontos $)$. Esse resultado concorda com os obtidos por Vaz et al. (2002c), que estudaram carcaças de vacas e novilhos da raça Hereford e observaram maior conformação nos animais mais jovens, enquanto Pacheco et al. (2005) diminuíram a idade de abate de 24 para 14 meses e não constataram modificação nessa característica.

Açougues e consumidores preferem carcaças com maior hipertrofia muscular, por seu melhor aspecto visual 
Tabela 3 - Conformação, espessura de coxão, perímetro de braço, área do músculo Longissimus dorsi e maturidade fisiológica da carcaça de novilhos e vacas de descarte terminados em confinamento com diversas frequencias de alimentação

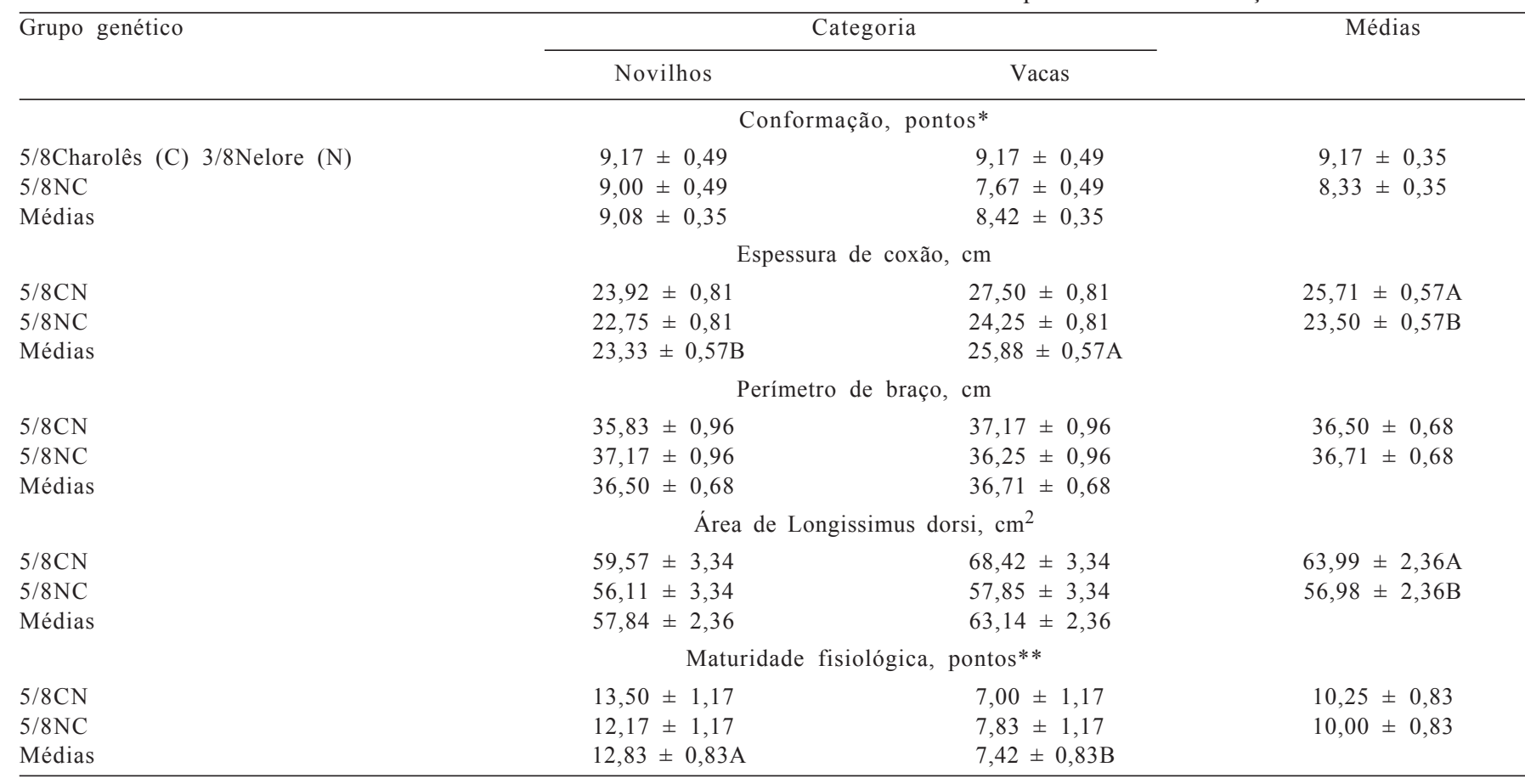

A,B Letras maiúsculas diferentes, na coluna ou na linha, diferem $(\mathrm{P}<0,05)$ no mesmo efeito, pelo teste ' $\mathrm{t}$ '.

* 1-3=inferior; 4-6=má; 7-9=regular; 10-12=boa; $13-15=$ muito boa; $16-18=$ superior.

** 1-3=acima de 8 anos de idade; $4-6=5,5$ a 8 anos de idade; 7-9=4 a 5,5 anos de idade; $10-12=2,5$ a 4 anos de idade; $13-15=$ menos de 2,5 anos de idade

(Müller, 1987), fato que comprova a importância de carcaças com altas pontuações de conformação. Animais da raça Charolesa se caracterizam por apresentar carcaça com maior expressão muscular, inclusive em cruzamentos (Vaz et al., 2002 a). No entanto, a geração do cruzamento Charolês $\times$ Nelore utilizada neste estudo (terceira) normalmente não expressa essa diferença, conforme verificado por Menezes et al. (2005) em novilhos jovens e Kuss et al. (2005) em vacas de descarte.

As vacas de descarte apresentaram maior $(\mathrm{P}<0,05)$ espessura de coxão em relação aos novilhos, possivelmente em virtude do peso de abate, tendo em vista a correlação alta e significativa entre ambos $(\mathrm{r}=0,73 ; \mathrm{P}<0,05)$ (Tabela 6). Além disso, quando ajustada para o mesmo peso de abate, a espessura de coxão deixou de ser significativa. Esses resultados discordam dos obtidos em trabalhos no Brasil (Restle et al., 2001; Vaz et al., 2002c), nos quais tem sido observada semelhança na espessura de coxão.

Os animais com maior predominância de sangue Charolês apresentaram maior espessura de coxão e área do músculo Longissimus dorsi, o que evidencia o efeito genético aditivo da raça Charolesa na expressão muscular da carcaça. Ao avaliarem diferentes raças taurinas e zebuínas, DeRouen et al. (1992) concluíram que a raça Charolês foi a que apresentou maior efeito genético para a característica área do músculo Longissimus dorsi.
Avaliando a segunda geração de cruzamento alternado entre as raças Charolesa e Nelore, Vaz et al. (2002d) verificou maior área do músculo Longissimus dorsi (ALD) $\left(70,8\right.$ vs $\left.65,9 \mathrm{~cm}^{2}\right)$ e ALD/100 kg PCF (28,7 vs 27,2 cm²) em novilhos $3 / 4 \mathrm{CN}$ em relação aos 3/4NC. No entanto, ao avaliarem a terceira geração desse mesmo cruzamento, alguns pesquisadores não observaram efeito da predominância racial nesses parâmetros de avaliação (Kuss et al., 2005; Menezes et al., 2005; Pacheco et al., 2005), o que demonstra que outros efeitos agem sobre essas características nesta geração.

O perímetro de braço, outra medida de musculosidade da carcaça, apresentou correlação significativa $(\mathrm{P}<0,05)$ com o peso de carcaça fria $(r=0,46)$, no entanto não foi observado efeito dos fatores em estudo para esta característica. Quando ajustada para o mesmo peso de abate os novilhos apresentaram maior $(\mathrm{P}=0,044)$ perímetro de braço em comparação às vacas $(37,72$ vs $35,50 \mathrm{~cm})$.

Apesar de constatada correlação significativa entre os pesos de carcaça e a área de Longissimus dorsi $(\mathrm{r}=0,81)$, não houve efeito $(\mathrm{P}>0,05)$ da categoria animal sobre esse parâmetro, embora as vacas tenham apresentado, numericamente, área de Longissimus dorsi 9,20\% superior, resultados contrários aos obtidos por Vaz et al. (2002c), com média significativamente superior para os novilhos em relação às vacas $\left(54,52\right.$ vs $\left.48,72 \mathrm{~cm}^{2}\right)$. 
Tabela 4 - Comprimentos de carcaça, de perna e de braço de novilhos e vacas de descarte terminados em confinamento com diversas frequencias de alimentação

\begin{tabular}{|c|c|c|c|}
\hline \multirow[t]{2}{*}{ Grupo genético } & \multicolumn{2}{|c|}{ Categoria } & \multirow[t]{2}{*}{ Médias } \\
\hline & Novilhos & Vacas & \\
\hline & \multicolumn{3}{|c|}{ Comprimento de carcaça, $\mathrm{cm}$} \\
\hline $5 / 8 \mathrm{NC}$ & $121,00 \pm 2,13$ & $128,67 \pm 2,13$ & $124,80 \pm 1,51 \mathrm{~B}$ \\
\hline \multirow[t]{2}{*}{ Médias } & $122,3 \pm 1,51 \mathrm{~B}$ & $132,8 \pm 1,51 \mathrm{~A}$ & \\
\hline & \multicolumn{2}{|c|}{ Comprimento de perna, $\mathrm{cm}$} & \\
\hline $5 / 8 \mathrm{NC}$ & $71,92 \pm 0,89$ & $71,75 \pm 0,89$ & $71,83 \pm 0,63$ \\
\hline \multirow[t]{2}{*}{ Médias } & $70,83 \pm 0,63$ & $72,38 \pm 0,63$ & \\
\hline & \multicolumn{2}{|c|}{ Comprimento de braço, $\mathrm{cm}$} & \\
\hline $5 / 8 \mathrm{CN}$ & $38,17 \pm 0,72$ & $39,17 \pm 0,72$ & $38,67 \pm 0,51$ \\
\hline $5 / 8 \mathrm{NC}$ & $39,00 \pm 0,72$ & $39,33 \pm 0,72$ & $39,17 \pm 0,51$ \\
\hline Médias & $38,58 \pm 0,51$ & $39,25 \pm 0,51$ & \\
\hline
\end{tabular}

A,B Letras diferentes, na coluna ou na linha, diferem $(\mathrm{P}<0,05)$ pelo teste $\mathrm{t}$.

Não houve interação $(\mathrm{P}>0,05)$ entre as categorias e os grupos genéticos estudados para as características métricas da carcaça (Tabela 4). O comprimento de carcaça foi maior $(\mathrm{P}<0,05)$ para os animais $5 / 8 \mathrm{CN}$ em relação ao grupo $5 / 8 \mathrm{NC}$ $(130,30$ vs $124,80 \mathrm{~cm})$. Restle et al. (1999) verificaram que a elevação da participação do sangue Nelore nos cruzamentos entre Nelore $\times$ Hereford diminuiu o comprimento de carcaça e aumentou o dos membros, e que as diferenças morfológicas entre as raças Bos taurus e Bos indicus e o efeito aditivo das duas raças foram responsáveis pela variação. Outros autores também citaram elevação do comprimento dos membros com maior participação de zebuínos no cruzamento (Restle et al., 1999; Vaz et al., 2002b), contudo, neste estudo não foi observada diferença entre os comprimentos de perna ou de braço entre os grupos genéticos avaliados.

As vacas de descarte foram superiores $(\mathrm{P}<0,05)$ aos novilhos quanto ao comprimento de carcaça $(132,8$ vs $122,3 \mathrm{~cm})$, e não houve diferença $(\mathrm{P}>0,05)$ para as demais medidas de desenvolvimento. Maior comprimento de carcaça em vacas de descarte abatidas em idade média de 8 anos de idade, em relação a novilhas abatidas aos 3 anos de idade, também é citado por Restle et al. (2001), mesmo resultado observado por Vaz et al. (2002c) ao trabalharem com novilhos e vacas de descarte da raça Hereford. Essa diferença no comprimento de carcaça entre as categorias se deve principalmente à diferença no peso de abate, uma vez que, ao se ajustar o modelo para o mesmo peso de abate, a diferença entre as categorias deixou de existir.

Houve interação significativa $(\mathrm{P}<0,05)$ entre grupo genético e categoria animal para o peso do costilhar (Tabela 5), tendo em vista a superioridade das vacas $5 / 8 \mathrm{CN}$ em relação às $5 / 8 \mathrm{NC}$, mas não houve efeito do grupo genético entre os novilhos. A raça Charolesa se caracteriza por apresentar carcaças com maior arqueamento de costelas em relação à raça Nelore, principalmente em virtude da maior pressão de seleção para aumento no consumo e no desempenho animal (Menezes et al., 2005). Além disso, em razão da presença uterina, vacas apresentam maior cavidade interna (Vaz et al., 2002d) afirmaram ainda que a deposição de gordura nesta região aumenta o peso deste corte e, consequentemente, seu percentual na carcaça, o que leva a uma correlação significativa entre espessura de gordura e porcentagem de costilhar, comprovada neste estudo ( $\mathrm{r}=0,65 ; \mathrm{P}<0,05$ - Tabela 6 )

Nos demais cortes não houve efeito $(\mathrm{P}>0,05)$ do grupo genético. Pouca variação entre grupos genéticos é encontrada para esses parâmetros na literatura. Luchiari Filho et al. (1985) observaram maior porcentagem de dianteiro em novilhos Nelore em relação aos mestiços e atribuíram esse resultado à presença do cupim. Resultado semelhante foi encontrado por Menezes et al. (2005) ao compararem novilhos puros Nelore e Charolês. Por outro lado, ao comparar animais dos grupos específicos utilizados neste artigo, Kuss et al. (2005), Menezes et al. (2005) e Pacheco et al. (2005) não observaram diferença no peso e no percentual na carcaça desses cortes.

Quanto ao efeito da categoria, as vacas tiveram maior peso do dianteiro, porcentagem de costilhar e peso de traseiro, resultados que estão relacionados ao maior peso de carcaça e à maior participação de gordura na carcaça nas vacas, uma vez que, segundo Berg \& Butterfield (1976), a deposição de gordura não só de cobertura, mas também a intramuscular, pode alterar a participação dos cortes comerciais na carcaça.

Os novilhos apresentaram maior $(\mathrm{P}<0,05)$ porcentagem de traseiro em relação às vacas. Em estudo com animais Charoleses, Restle et al. (2000) relataram que vacas de 
Tabela 5 - Pesos absoluto e percentual de traseiro, dianteiro e costilhar da carcaça de novilhos e vacas de descarte terminados em confinamento com diversas frequencias de alimentação

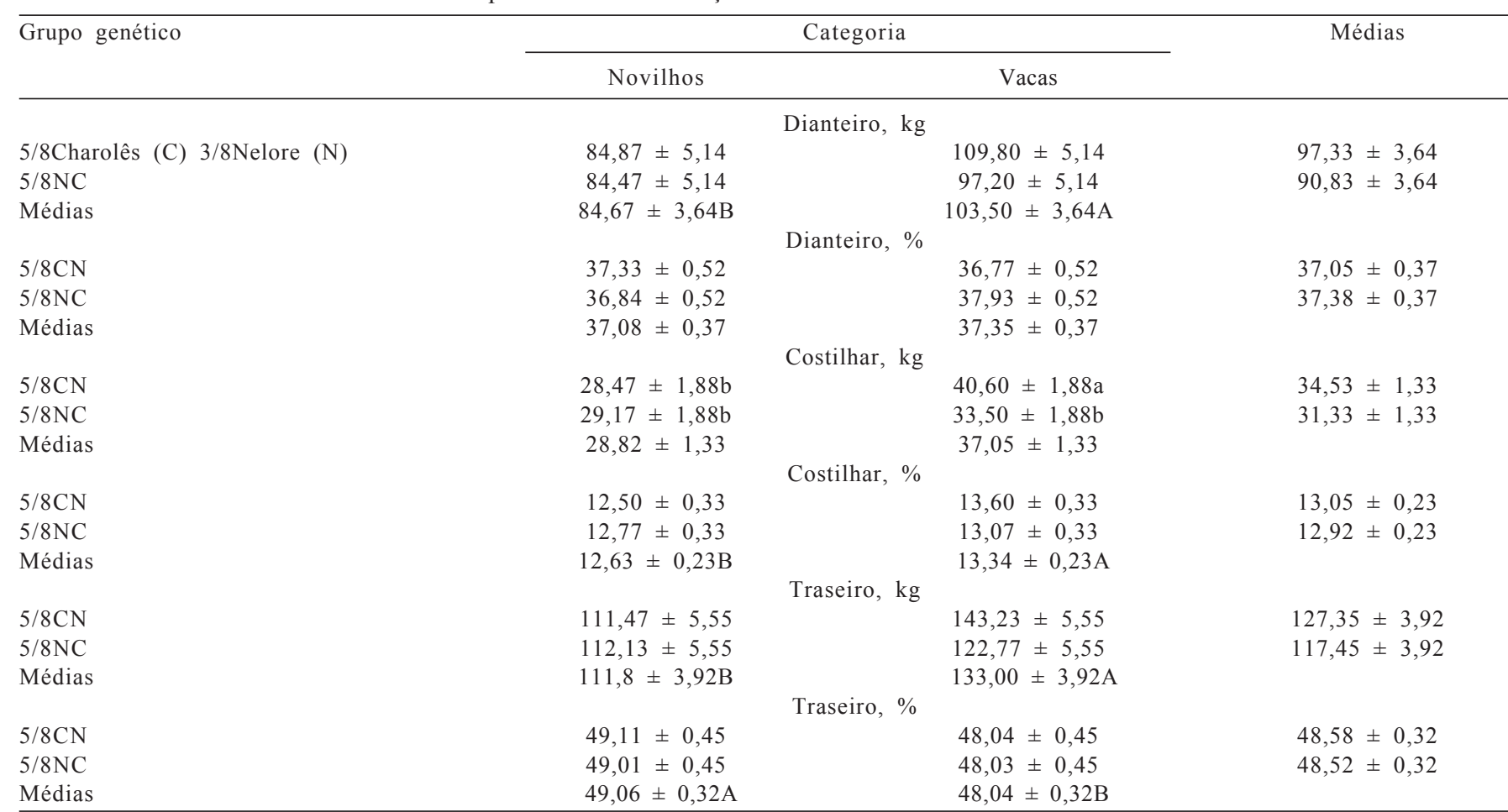

a, b, Médias seguidas por letras minúsculas diferentes, para a mesma característica, diferem $(\mathrm{P}<0,05)$ pelo teste $\mathrm{t}$.

A,B Letras maiúsculas diferentes na coluna ou na linha diferem $(\mathrm{P}<0,05)$ pelo teste $\mathrm{t}$.

Tabela 6 - Coeficientes de correlação de Pearson gerais entre os parâmetros quantitativos da carcaça de novilhos e vacas $5 / 8$ Charolês Nelore $(5 / 8 \mathrm{CN})$ e $5 / 8 \mathrm{NC}$ terminados em confinamento

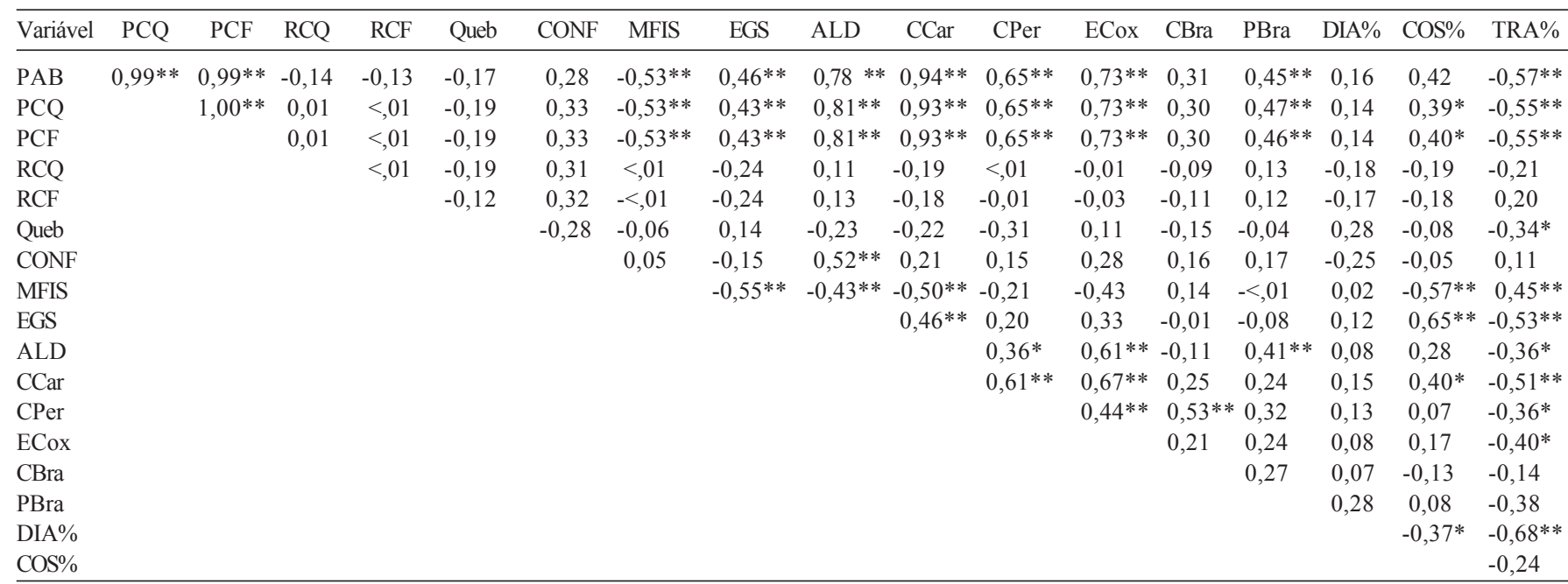

* $\mathrm{P}<0,10 ; * * \mathrm{P}<0,05 ; * * * \mathrm{P}<0,01$

$\mathrm{PAB}=$ peso de abate $\mathrm{PCQ}=$ peso de carcaça quente $\mathrm{PCF}=$ peso de carcaça fria $\mathrm{RCQ}=$ rendimento de carcaça quente; $\mathrm{RCF}=$ rendimento de carcaça fria; $\mathrm{Queb}=$ quebra no resfriamento; CONF = conformação; MFIS = maturidade fisiológica; EGS = espessura de gordura subcutânea; ALD = área do músculo Longissimus dorsi; Ccar = comprimento de carcaça; Cper = comprimento de perna; Ecox = espessura de coxão; Cbra = comprimento de braço; Pbra $=$ perímetro de braço; DIA $\%=$ porcentagem de dianteiro; $\operatorname{COS} \%=$ porcentagem de costilhar; TRA $\%=$ porcentagem de traseiro

descarte abatidas com 4 anos de idade apresentaram valores de traseiro superiores aos de animais entre 7 e 9 anos de idade, assim como Restle et al. (2001) verificaram maior porcentagem de traseiro nas novilhas em relação às vacas. Essa superioridade dos animais jovens na participação de traseiro na carcaça é desejável, uma vez que a maioria dos cortes nobres presentes na carcaça se encontra nesta porção. 


\section{Conclusões}

O aumento na frequencia de alimentação não influencia as características de carcaça de novilhos e vacas terminadas em confinamento. Animais 5/8Charolês-Nelore são superiores em algumas características que expressam musculosidade (espessura de coxão e comprimento de carcaça) em relação a animais 5/8 Nelore - Charolês. Vacas de descarte terminadas em confinamento apresentam carcaças de maior qualidade (mais pesadas, com maior espessura de gordura subcutânea e de coxão) em comparação a novilhos, com exceção da participação do corte traseiro na carcaça, que é maior nos novilhos.

\section{Literatura Citada}

ANUÁRIO DA PECUÁRIA BRASILEIRA - ANUALPEC 2006. Anuário estatístico da produção animal. São Paulo: Prol Editora Gráfica, 2006. 364p.

ARBoitTe, M.Z.; Restle, J.; ALVES Filho, D.C. et al. Características da carcaça de novilhos $5 / 8$ Nelore - $3 / 8$ Charolês abatidos em diferentes estádios de desenvolvimento. Revista Brasileira de Zootecnia, v.33, n.4, p.969-977, 2004.

BERG, R.T.; BUTTERFIELD, R.M. New concepts of cattle growth. Sydney: Sydney University Press, 1976. 240p.

CATELlam, J.; MENEZES, L.F.G.; FERREIRA, J.J. et al. Características das partes do corpo não-integrantes da carcaça de novilhos e vacas de descarte de diferentes grupos genéticos. Ciência Animal Brasileira, 2009. (no prelo).

CHASE, L.J.; WANGSNESS, P.J.; BAUMGARDT, B.R. Feeding behaviour of stress fed a complete mixed ration. Journal of Dairy Science, v.59, n.11, p.1923-1928. 1976.

DeROUEN, S.M.; FRANKE, D.E.; BIDNER, T.D. et al. Direct and maternal genetic effects for carcass traits in beef cattle. Journal of Animal Science, v.70, n.12, p.3677-3685, 1992.

DI MARCO, O.N. Crecimiento de vacunos para carne. Mar Del Plata: Oscar N. Di Marco, 1998. 246p.

FATURI, C.; RESTLE, J.; BRONDANI, I.L. et al. Características da carcaça e da carne de novilhos de diferentes grupos genéticos alimentados em confinamento com diferentes proporções de grão de aveia e grão de sorgo no concentrado. Revista Brasileira de Zootecnia, v.31, n.5, p.2024-2035, 2002.

FISHER, V.; DESWYSEN, G.A.; DUTILlEUL, P. et al. Padrões da distribuição nictemeral do comportamento ingestivo de vacas leiteiras, ao início e ao final da lactação, alimentadas com dieta à base de silagem de milho. Revista Brasileira de Zootecnia, v. 31, n.5, p.2129-2138, 2002.

GALVÃO, J.G.; FONTES, C.A.A.; PIRES, C.C. et al. Características e composição da carcaça de bovinos não-castrados, abatidos em três estágios de maturidade (estudo 2) de três grupos raciais. Revista da Sociedade Brasileira de Zootecnia, v.20, p.502-512, 1991.

JARDIM, P.O.C.; GUARENTI, N.M.; OSÓRIO, J.C.S. et al. Avaliação dos cortes dianteiro, costilhar e serrote em vacas de descarte. Pesquisa Agropecuária Brasileira, v.23, n.5, p.543-549, 1988.

KOGER, M. Effective crossbreding systems utilizing zebu cattle. Journal of Animal Science, v.50, n.6, p.1213-1220, 1980.

KUSS, F.; RESTLE, J.; BRONDANI, I.L. et al. Características da carcaça de vacas de descarte de diferentes grupos genéticos terminadas em confinamento com distintos pesos. Revista Brasileira de Zootecnia, v.34, n.3, p.915-925, 2005.

LUCHIARI FILHO, A.; BOIN, C.; ALLEONI, G.F.; et al. Efeito do tipo de animal no rendimento da porção comestível da carcaça.
I. Machos da raça Nelore vs cruzados Zebu x europeu terminados a pasto. Boletim da Indústria Animal, v.42, n.2, p.143-148, 1985.

MENEZES, L.F.G.; RESTLE, J.; BRONDANI, I.L. et al. Órgãos internos e trato gastrintestinal de novilhos de gerações avançadas do cruzamento rotativo entre as raças Charolês e Nelore terminados em confinamento. Revista Brasileira de Zootecnia, v.36, n.1, p.120-129, 2007

MENEZES, L.F.G.; RESTLE, J.; BRONDANI, I.L. et al. Características da carcaça de novilhos de gerações avançadas do cruzamento alternado entre as raças Charolês e Nelore, terminados em confinamento. Revista Brasileira de Zootecnia, v.34, n.3, p.934-945, 2005 .

MÜLLER, L. Normas para a avaliação de carcaças e concurso de carcaças de novilhos. 2.ed. Santa Maria: Universidade Federal de Santa Maria, 1987. 31p.

PACHECO, P.S.; SILVA, J.H.S.; RESTLE, J. et al. Características quantitativas da carcaça de novilhos jovens e superjovens de diferentes grupos genéticos. Revista Brasileira de Zootecnia, v.34, n.5, p.1666-1677, 2005

PEROBELLI, Z.V.; RESTLE, J.; MÜLLER, L. Estudo das carcaças de vacas de descarte das raças Charolês e Nelore. Pesquisa Agropecuária Brasileira, v.30, n.3, p.409-412, 1995.

RESTLE, J.; CERDÓTES, L.; VAZ, F.N. et al. Características da carcaça e da carne de novilhas e vacas de descarte Charolês, terminadas em confinamento. Revista Brasileira de Zootecnia, v.30, n.3, p.1065-1073, 2001

RESTLE, J.; PASCOAL, L.L.; FATURI, C. et al. Efeito do grupo genético e da heterose nas características quantitativas da carcaça de vacas de descarte terminadas em confinamento Revista Brasileira de Zootecnia, v.31, n.1, p.350-362, 2002.

RESTLE, J.; ROSO, C.; OLIVEIRA, A.N. et al. Suplementação energética para vacas de descarte de diferentes idades em terminação em pastagem cultivada de estação fria sob pastejo horário. Revista Brasileira de Zootecnia, v.29, n.4, p.1216-1222, 2000.

RESTLE, J.; VAZ, F.N.; QUADROS, A.R.B. Características de carcaça e da carne de novilhos de diferentes genótipos de Hereford x Nelore. Revista Brasileira de Zootecnia, v.28, n.6, p.1245-1251, 1999.

STATISTICAL ANALYSIS SYSTEM - SAS. SAS/STAT User's guide statistics. 4.ed. Cary: 1997. v.2, 943p.

VAZ, F.N.; RESTLE, J. Produção de carne com qualidade. In: RESTLE, J.; BRONDANI, I.L.; PASCOAL, L.L. et al. (Eds.) Produção intensiva com qualidade em bovinos de corte. Santa Maria: Universidade Federal de Santa Maria, 1998. p.104-119.

VAZ, F.N.; RESTLE, J.; ALVES FILHO, D.C. et al. Peso das vísceras e rendimento de carcaças de novilhos ou novilhas Braford superprecoces, terminados com suplementação em pastagem cultivada com pastejo controlado. In: REUNIÃO ANUAL DA SOCIEDADE BRASILEIRA DE ZOOTECNIA, 38., 2001, Piracicaba. Anais... Piracicaba: Fundação de Estudos Agrários "Luiz de Queiroz", 2001. p.1531-1532.

VAZ, F.N.; RESTLE, J.; ALVES FILHO, D.C. et al. Características de carcaça e da carne de novilhos filhos de vacas $1 / 2$ Nelore $1 / 2$ Charolês e $1 / 2$ Charolês $1 / 2$ Nelore acasaladas com touros Charolês ou Nelore. Revista Brasileira de Zootecnia, v.31, n.4, p.1734-1743, 2002a.

VAZ, F.N.; RESTLE, J.; PACHECO, P.S. et al. Características de carcaça e da carne de novilhos superprecoce de três grupos genéticos, gerados por fêmeas de dois anos. Revista Brasileira de Zootecnia, v.31, n.5, p.1973-1982, 2002b.

VAZ, F.N.; RESTLE, J.; QUADROS, A.R.B. et al. Características da carcaça e da carne de novilhos e de vacas de descarte Hereford, terminados em confinamento. Revista Brasileira de Zootecnia, v.31, n.3, p.1501-1510, 2002c (supl.).

VAZ, F.N.; RESTLE, J.; VAZ, R.Z. et al. Efetitos de raça e heterose na composição física da carcaça e na qualidade da carne de novilhos da primeira geração de cruzamento entre Charolês e Nelore. Revista brasileira de Zootecnia, v.21, n.1, p.376-386, 2002d (supl.). 